\title{
Characteristics of Medical Services in the US Versus Saudi Arabia
}

\author{
Ibrahim Saad Alsumaih ${ }^{1}$, Fahad Abdulaziz Aldhuwayhi ${ }^{2}$ \\ ${ }^{1}$ Home Health Care, Prince Saud Bin Jalawi Hospital, Al Ahssa, Saudi Arabia \\ ${ }^{2}$ Nursing office and Emergency department in Howtat Sudair Hospital, Riyadh, Saudi Arabia
}

Email address:

dr.sumaih@hotmail.com (I. S. Alsumaih), Fahad.aziz@yahoo.com (F. A. Aldhuwayhi)

\section{To cite this article:}

Ibrahim Saad Alsumaih, Fahad Abdulaziz Aldhuwayhi. Characteristics of Medical Services in the US Versus Saudi Arabia. Science Journal of Public Health. Vol. 3, No. 4, 2015, pp. 588-591. doi: 10.11648/j.sjph.20150304.29

\begin{abstract}
The scholarships provided by the Saudi Arabian government have made it possible for many students to acquire higher education in the United States (U.S.). The students have the privilege of comparing aspects between the two countries. The survey that is outlined in this paper shows that many students perceive medical services in the U.S. as being better than those provided in Saudi Arabia (SA). The survey was conducted in March 2015. Some 1,299 students participated in filling out online questionnaires. After ineligibles were excluded, some 663 participants were selected for the study. The variables of interest were health complaints as well as the perception that these services are better in the U.S. than in SA. Measures of tendency were presented, and independent t-tests were performed. The chi-square test was also used to find any relationships between income and clinic visits. The chi-square tests indicated no association and the t-test showed that the perception of many students favored the U.S. health care systems (US Department of state, 2015) Further research was also carried out in order to find the probable reason for students' feedbacks. After analyzing several pieces of literature, no differences were found in technological advances between the two countries. However, the approaches of delivering health services were found to differ in terms of patient-doctor relationship. (M, G, \& M, 2011)
\end{abstract}

Keywords: Healthcare in Saudi Arabia, Healthcare in United States, Perception, Differences

\section{Background}

Every year, the SA government provides academic and financial opportunities for Saudi students to study abroad, particularly in the United States. A report called "Open Doors" has indicated that Saudi students are surging in numbers in the United States. (A, A, \& A, 2001) The report also shows that SA is ranked fourth as an exporter of students to the United States (Iie.org). Being in a foreign country does not eliminate the probability that one could get sick. Diseases are everywhere. However, healthcare services are not equally matched in all countries. Saudi students in the U.S. are exposed to health services from both countries and can therefore tell the difference between these services in terms of cost and quality. (website, 2014)

\section{Objectives}

This investigation aims to analyze the demographic and medical-related characteristics of Saudi students who studied overseas, specifically in the US. The goal is to measure if the mean number of annual visits to a medical clinic differs by a perception of U.S. medical services being better than in Saudi Arabia (SA). This study will also assess whether there is an association between student's income and the perception that the medical services in the U.S. are better than in Saudi Arabia. Furthermore, the association between student's main health complaints and the aforementioned perception will also be evaluated. Students' health complaints will be visualized graphically. The graphs will provide a suitable comparison of the differing views. (J, 2013)

\section{Methods}

Between March 8 and 18th, 2015, an online survey targeting Saudi students was sent to Facebook pages belonging to several Saudi college students' groups. A web link was provided to access the questionnaire. A total of 1,299 students clicked on the link, 370 eligible Saudi students were excluded due to an incomplete survey and 225 were not Saudi and thus ineligible. Thus, a total of 704 completed the 28 question survey; however, only 663 of 
those participants were located in the U.S. Variables were selected according to the relevance with the study. Demographic variables gathered were age, sex, education level, marital status, and income. The categorical variables of interest were main health care service complaints; perception that medical services in the U.S. are better than in SA; and perceiving that health insurance is a viable option in Saudi Arabia. Measures of central tendency and dispersion were presented for continuous variables such as number of annual visits to a medical clinic, and number of times a U.S. medical clinic or hospital was visited for an emergency. Assuming the data comes from a simple random sample, two independent sample t-tests were performed to measure if the mean number of annual visits to a medical clinic differed by having a perception that U.S. medical services were better than in SA. Equality of variance test was performed. Additionally, chi-square was utilized to assess the association between student's main health complaint and 1), the perception that the medical services in the U.S. are better compared to SA 2) perceiving health insurance in SA as a viable option and 3) students' income level. (Ling, 2008). The expected frequency count for each cell of the table was assessed; therefore Fisher's exact test was used since a few cells had a count less than 5. Statistical significance was assessed via $p$-values. The SAS statistical software (9.4) was used to perform the analyses.

\section{Results}

The average age of Saudi students was 27 years old $(26.55$ \pm 4.54 ). The percentages of students studying abroad in the U.S., based on male or female gender were $77.64 \%$ and $22.36 \%$ respectively. Around $50 \%$ had a college or postgraduate degree, $44.56 \%$ were married, and $44.11 \%$ had an income between $\$ 20,000$ and $\$ 39,999$. As for health care services, the mean number of annual visits to a medical clinic was $4(4.40 \pm 5.77)$. The mean number of visits to a medical clinic or hospital for an emergency was $3(3.13 \pm 8.10)$. The majority $(98.04 \%)$ of the participants were insured by Aetna PPO health insurance. More than $80 \%$ perceive that U.S. health care services are better than in SA. Around $84 \%$ of Saudi students believe that health insurance in Saudi Arabia is a viable option. The main health care complaint that students had came from medical services $(47.96 \%)$ followed by dental $(29.65 \%)$ (Table 1$)$. Folded $\mathrm{F}$ method statistics (Folded F method p-value $<.0001<\alpha=0.05$ ) showed that the variance of annual visits to a medical clinic from Saudi students who perceived U.S. medical services as being better than in Saudi Arabia (variance: 36.62) was higher than those who didn't (variance: 17.23). A two-sample Satterthwaite ttest suggests, at a $95 \%$ significance level, that the mean number of Saudi student's visits to a medical clinic who perceive U.S. medical services as being better than Saudi Arabia (4.60 [95\%CI 4.10-5.11]) differ with those who don't perceive so $(3.50$ [95\%CI 2.74-4.26]) (p-value $=0.0184)$ (Table 2). On the other hand, the chi-square test showed that there is no statistical association between income levels and the visits to a medical clinic in the pervious year ( $\mathrm{p}$-value $=$ 0.6585). Additionally, main health complaints from Saudi students were not significantly associated with the perception that U.S. medical services were better than in Saudi Arabia ( $\mathrm{p}$-value $=0.7238$ ) or with the perception that health insurance was a viable option in SA (p-value $=0.5579)$ (Table 3).

Table 1. Characteristics of Saudi students studying in the United States.

\begin{tabular}{lll}
\hline & $\begin{array}{l}\text { Sample } \\
\text { size (n) }\end{array}$ & $\begin{array}{l}\text { Percentage } \\
(\mathbf{\%})\end{array}$ \\
\hline Demographics & & \\
Age (mean \pm SD) & 662 & $26.55 \pm 4.54$ \\
Sex & & \\
Male & 514 & 77.64 \\
Female & 148 & 22.36 \\
Education & & \\
Some high school & 64 & 9.67 \\
High school diploma & 120 & 18.13 \\
Some college/associate or technical degree & 137 & 20.69 \\
College/post graduate or professional school & 341 & 51.51 \\
Marital status & & \\
Single & 360 & 54.38 \\
Married & 295 & 44.56 \\
Divorced & 6 & 0.91 \\
Widowed & 1 & 0.15 \\
Income & & \\
\hline \$0-19,999 & 168 & 25.38 \\
\hline \$20,000-39,999 & 292 & 44.11 \\
\$40,000-74,999 & 169 & 25.53 \\
\hline \$75,000 & 33 & 4.98 \\
\hline Health care services & & \\
Times visited US medical clinic \\
(mean \pm SD)
\end{tabular}

Table 2. T-test results.

\begin{tabular}{llr}
\hline & \multicolumn{2}{l}{ Number of medical clinic visits } \\
\hline & Mean $(95 \% \mathrm{CI})$ & $\mathrm{P}$ value \\
$\begin{array}{l}\text { Perception that medical } \\
\text { services are better in the U.S. }\end{array}$ & 0.0184 \\
Yes & $4.60(4.10-5.11)$ & \\
No & $3.50(2.74-4.26)$ & \\
\hline
\end{tabular}


Table 3. Chi-square test results.

\begin{tabular}{|c|c|c|c|c|}
\hline & \multicolumn{4}{|c|}{ Visits to a medical clinic in the last year } \\
\hline & $0-4$ & $5-9$ & $10+$ & P-value \\
\hline Income Levels & $\mathrm{n}$ & $\mathrm{n}$ & $\mathrm{n}$ & 0.6585 \\
\hline$\$ 0-\$ 19,999$ & 121 & 28 & 18 & \\
\hline$\$ 20,000-\$ 39,999$ & 198 & 59 & 35 & \\
\hline$\$ 40,000-\$ 74,999$ & 120 & 24 & 25 & \\
\hline \multirow[t]{2}{*}{$>\$ 75,000$} & 23 & 5 & 5 & \\
\hline & \multicolumn{3}{|c|}{ Perception that medical services are better in the U.S. } & \\
\hline Health care area & Yes & No & 0.7238 & \\
\hline Dental & 164 & 32 & & \\
\hline Medical & 255 & 62 & & \\
\hline Physiotherapy & 27 & 6 & & \\
\hline \multirow[t]{3}{*}{ Ophthalmologist } & 97 & 18 & & \\
\hline & \multicolumn{3}{|c|}{ Perception that health insurance is a viable option in SA } & \\
\hline & $\mathbf{n}$ & $\mathbf{n}$ & P value & \\
\hline Medical & 259 & 58 & & \\
\hline Physiotherapy & 27 & 6 & & \\
\hline Ophthalmologist & 99 & 16 & & \\
\hline
\end{tabular}

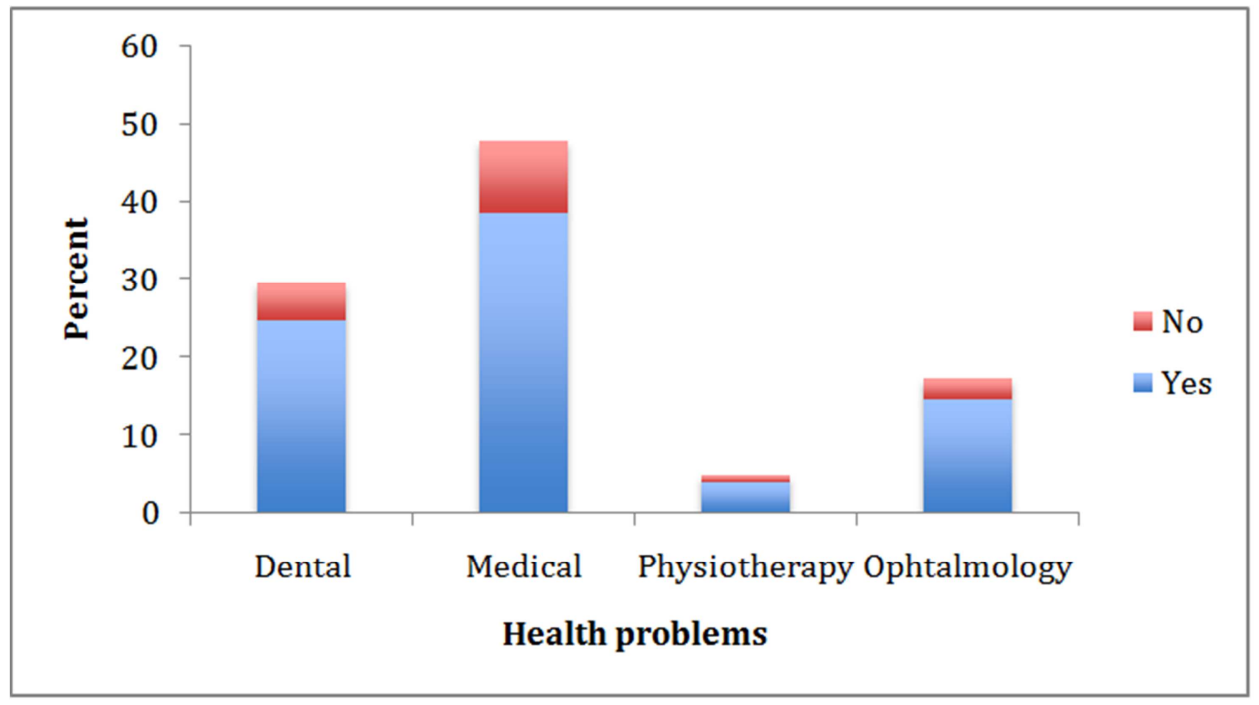

Figure 1. Perception that U.S. health care services are better than in Saudi Arabia by health problems.

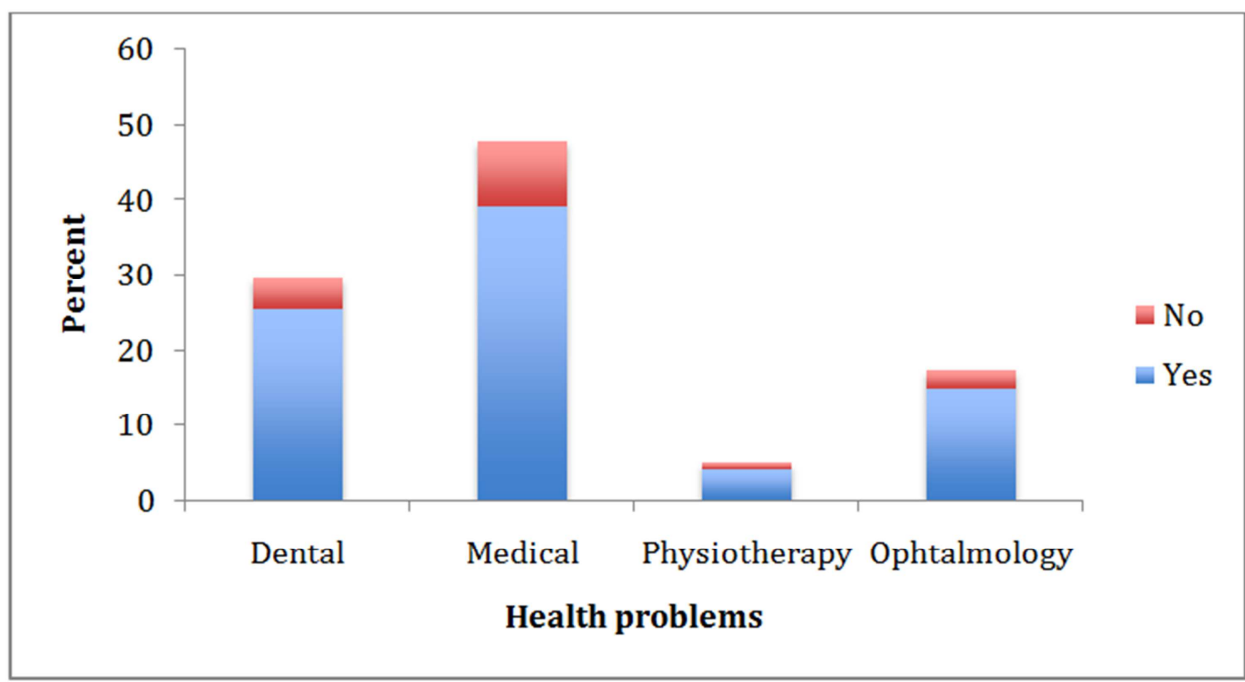

Figure 2. Perception that health insurance in Saudi Arabia is a viable option by health problems. 


\section{Discussion}

The results of the study show that many students hold the perception that U.S. health care services are better than those in Saudi Arabia. It is, therefore, necessary to find out why the students cling to this belief. A review of several literatures pieces provides the differences between each healthcare system in terms of service delivery, technology, and doctorpatient relationships.

The U.S is viewed as an advanced country in terms of development and technology. Many people admire the country. The statistics outlined in this study give a clear picture of the views of the Saudi Arabian students in the U.S. The systems of health care in Saudi Arabia are developing exponentially. However, the United States has one of the best systems of health care in the globe. It is hard to choose a different country over the U.S. when statistics show it is better in terms of health care (American Bedu).

The medical systems in the U.S and Saudi Arabia have many similarities. Almost all of the diseases are treated in the same manner. Similar types of medicines are administered as a way of treatment. However, there are some differences too. For instance, there are differences in cultural practices in the countries. Female doctors and nurses in Saudi Arabia dress differently from those working in America. The modes of dressing might have a profound impact on the doctor-patient relationships. A patient may be free to converse with a doctor who exposes her whole face compared to a doctor who puts on a hijab. On the other hand, many people feel that the doctors and nurses in America are less compassionate than those in Saudi Arabia. In Saudi Arabia, the culture allows people to have large families. Many people are allowed to visit a patient at the hospital. The large number of visitors might become difficult to manage, and the delivery of healthcare could be jeopardized. For one to receive health care in the United States, he or she must provide proof of insurance and pay some upfront fees. However, this is not the case in SA. It is certainly hard to tell which country is better in terms of technology. The most obvious differences in the healthcare systems are the result of differences in culture.

\section{Conclusions}

The mean number of Saudi students who perceive that the medical services in the U.S are better than those in Saudi Arabia is higher than those who believe otherwise. The chisquare test has shown that there is no association between income levels and annual visits to clinics. The results of the chi-square test provide a high degree of validity. This is also based on the logic that a hospital is solely a place for the sick, and not for those who can simply afford it. The final discovery was that there was no association between students' medical health complaints and the perception that U.S. medical services are better than in Saudi Arabia or with the perception that health insurance is a viable option in SA. (R, 2015)

Research from previous studies has tried to identify the differences in these perceptions. Even though it is hard to tell which country offers the best healthcare services, it is evident that service delivery is different. The main differences occur in the style of delivery rather than the quality. Research has shown that culture is emphasized more in SA than in the United States. On the other hand, the medical practitioners in SA seem to be more friendly than those in the U.S. Although different, both countries provide excellent health care service delivery.

\section{References}

[1] American Bedu,. 'Comparison Of Health Care Between USA And KSA'. N.p., 2009. Web. 13 May 2015.

[2] Iie.org,. 'Open Doors 2014 Report'. N.p., 2015. Web. 13 May 2015.

[3] A, Z., A, W., \& A, a. (2001). Health Care Services In SaudI Arabia: Past Present Future. Journal of Family and Community Medicine .

[4] J, S. (2013). Population Research. Journal on population research .

[5] Ling, $\quad$ F http://www.ling.upenn.edu/ clight/chisquared.htm.

[6] M, A., G, F., \& M, C. (2011). Health Care System in Saudi Arabia:An Overview. Health Care System in Saudi Arabia:An Overview .

[7] $\mathrm{R}$, D. http://saudiarabia.angloinfo.com/healthcare/healthsystem/medical-insurance/.

[8] US Department of state. (2015). http://www.state.gov/m/med/.

[9] website. http://en.wikipedia.org/wiki/Health_care_in_the_United_State s. Retrieved 2014

[10] A, Z., A, W., \& A, a. (2001). Health Care Services In SaudI Arabia: Past Present Future. Journal of Family and Community Medicine

[11] J, S. (2013). Population Research. Journal on population research .

[12] Ling, $\quad$ F. http://www.ling.upenn.edu/ clight/chisquared.htm.

[13] M, A., G, F., \& M, C. (2011). Health Care System in Saudi Arabia:An Overview. Health Care System in Saudi Arabia:An Overview .

[14] R, D. http://saudiarabia.angloinfo.com/healthcare/healthsystem/medical-insurance/.

[15] US Department of state. (2015). http://www.state.gov/m/med/.

[16] website. http://en.wikipedia.org/wiki/Health_care_in_the_United_State s. Retrieved 2014. 